\title{
Review on ICF-related Research Trends in Korean Clinical Field
}

\author{
Ju-Min Song, PT, PhD
}

Department of Physical Therapy, Silla University

Received: September 16, 2021 / Revised: September 17, 2021 / Accepted: October 12, 2021

(C) 2021 J Korean Soc Phys Med

\begin{abstract}
| Abstract |
PURPOSE: This study analyzed the research trends related to the International Classification of Functioning, Disability, and Health (ICF) to suggest an ICF utilization plan in the Korean clinical field.
\end{abstract}

METHODS: In the RISS, KISS, NSDL, and PubMed databases, papers published between 2016 and July 2021 were collected by applying the search terms, 'ICF', 'international classification of functioning, disability and health', 'clinic', 'patient', and 'diagno'. The 44 papers selected were classified according to the analysis criteria, and the frequency and percentage were calculated.

RESULTS: In domestic clinical trials, the frequency of ICF-related studies was in the order of physical therapy $(\mathrm{n}=$ 19) and occupational therapy $(n=14)$. The frequency of each study subject was observed in the order of studies related to a specific disease $(n=34)$ and prior studies $(n=7)$. The research topics were in the order of studies using ICF as a measurement tool $(n=21)$ and case studies with patients with

Corresponding Author: Ju-Min Song jmsong@silla.ac.kr, https://orcid.org/0000-0001-8469-3550 This is an Open Access article distributed under the terms of the Creative Commons Attribution Non-Commercial License (http://creativecommons.org/licenses/by-nc/3.0) which permits unrestricted non-commercial use, distribution, and reproduction in any medium, provided the original work is properly cited. specific diseases $(n=11)$. There were 18 studies using ICF codes and 14 papers applying the ICF domains.

CONCLUSION: Over the last five years, ICF-related research in the domestic clinical field targeted patients with more diverse diseases in more expertise fields. Research for the unification of terms should be conducted for communication among various experts in clinical practice. To promote the use of ICF in the clinical field, it will be necessary to conduct research, such as the unification of terms, standardized education, development of ICF casebook, and development of ICF coding programs and guidelines.

Key Words: Clinical field, Disability, Functioning, ICF

\section{Introduction}

Functioning is an umbrella term that expresses the degree of an individual's physiological function, anatomical structure, ability to perform daily living, and participation in various areas of life. It interacts with environmental factors that affect individual and personal factors, including age, gender, and health status, and can indicate the degree of limitations and restrictions around life in which the person lives [1,2].

An evaluation of functioning is generally performed in the clinical field for a diagnosis of disease, treatment planning, evaluation of the treatment effect, and identification of 
disability. In addition, functioning-related information is essential at all levels of the medical system, such as treatment, service revision, management, and policy. Therefore, the degree of functioning should be evaluated from various aspects [3].

The World Health Organization recognized the need for a model and information system that can explain the effects of disease on functioning, and published the ICF in 2001. It is based on a biopsychosocial model that consists of the body function and structure, activity and participation, and environmental factors. Hence, health and healthrelated information can be classified from multiple perspectives. The four domains interact and affect the degree of an individual's functioning and disability [1]. Each domain is composed of chapters that include two-level and three-level codes below it. The three-level code, which is the lowest structure, can express more detailed information. Qualifiers from 0 to 4 written after a code can indicate the degree of difficulty, barrier, and facilitation of that code $[4,5]$.

ICF is being used as a common language to communicate functioning-related information among users in various fields, such as health professionals, researchers, policymakers, and educators [6]. It is becoming common for clinicians to use the ICF framework to classify functioning information and structure treatment goals [7].

Since ICF was developed in 2001, ICF-related research on various topics has been reported in various fields. Recently, ICF-related research has focused mainly on the validity of the ICF core set, development of a new functioning evaluation tool, and development of a core set appropriate for the situation of the country, how to use ICF for better understanding and correct use of ICF [2,8-10]. Research on how to use ICF is essential because it can seek ways to understand ICF properly and apply it correctly. Through trend analysis of related prior research, it is possible to determine an application plan in the process of presenting research problems and research directions.
In addition, such a utilization plan should be devised to maintain the character of a standard classification while reflecting the characteristics of the country or specialized field.

ICF-related research is being conducted in various fields in Korea. Most research has been reported in the clinical field [11,12]. In the clinical field, studies have been performed on the following: to evaluate the change in a patient's functioning before and after treatment, review previous ICF studies, develop and analyze an evaluation tool using ICF, and confirm the possibility of applying ICF and apply methods. Case studies are presented. On the other hand, there are insufficient reports on ICF-related research trends and ICF utilization plans in the clinical field. In the clinical area, it can be helpful to find ways to promote the use of ICF by examining the usage trends of which level or type used ICF for what purpose. Therefore, this study examined the trends of ICF-related research in the domestic clinical field to suggest a plan to utilize ICF to be used actively as a standard classification in the clinical field.

\section{Methods}

\section{Search Methods and Selection Criteria for} Subjects

A literature search was conducted for four weeks from July 2021 to investigate the trend of ICF-related research in the domestic clinical field. As domestic databases, RISS of the Korea Education and Research Information Service, KISS of Korean Studies Information, and NDSL of National Digital Science Library were used.

The search terms used for the literature search were 'ICF', 'international classification of functioning, disability and health', and '국제기능장애건강분류', and the operator 'or' was used between them.

In the papers collected, papers with 'clinic', 'patient', 'diagnos', 'clinical', 'patient', or 'diagnosis' in the title, 
abstract, and keywords were selected. PubMed was used to search for papers published in foreign journals, and the search term 'Korean' was added to proceed in the same manner as in the domestic database.

The inclusion criteria for the selection of papers for this study are as follows. First, the papers have a title, an abstract, or a keyword that includes these search terms. Second, among the papers published from 2016 to July 2021, the ICF was applied, and the studies were conducted in Korea and included Korean authors. Third, in the case of papers published in Korea, they appeared in journals registered in the National Research Foundation of Korea and candidate journals that require peer-review. Fourth, the papers were published within the last five years.

Studies that met the following exclusion criteria were excluded: papers, in which "ICF" does not mean "international classification of functioning, disability and health"; articles published in journals other than those registered in the National Research Foundation of Korea and candidate journals; studies that do not apply the ICF framework or codes; and publications in foreign clinical settings, though they were published in either of the aforementioned domestic journals.

During this period, 88 papers (51 from RISS, 18 from KISS, 16 from NDSL, and three from PubMed. were collected after a search using the suggested keywords. After deleting 37 duplicate papers, the abstracts and texts of 44 papers were read to confirm the inclusion and exclusion criteria.

Forty-four papers were selected as research subjects, excluding the following papers: three papers where ICF does not mean 'international classification of functioning, disability and health', one thesis for students with disabilities in the field of special education, one paper including clinical analysis in the ICF core-set utilization trend analysis study, one systematic review of dementia patients in the field of social welfare, and one paper on an investigation of the correlations related to stroke patients.

\section{Analysis Criteria for Subjects}

For the analysis of the selected papers, the analysis framework reported in previous studies was modified and applied [11,12]. A coding process was carried out for the title of the paper, researcher's area of expertise, type of research subjects, level of ICF applied in the study, domains of the ICF used in the study, research topic, year of publication, names of the researchers, and the name of the published journal and main issue.

Based on the coding contents, the selected papers were classified into oriental medicine, medical information, neurology, occupational therapy, otolaryngology, physical therapy, and rehabilitation medicine according to the area of expertise of the principal researcher, and the frequency was confirmed. The types of study subjects were divided into patients, prior thesis, expert, and insurance fee. In studies where the subjects were patients, patients were classified by disease-related body system.

Research topics were classified into an evaluation of functioning using ICF, a case study of applying ICF, review on ICF, tool development using ICF, analysis of existing measurement tools using ICF, treatment planning using ICF, and insurance fee analysis using ICF. The studies that evaluated subjects for measurement tool analysis or development were processed in duplicate in the evaluation, tool analysis, and development.

The ICF domains used in the study subjects were classified into the physical function, physical structure, activity and participation, and environmental factors. The level of ICF applied in the research paper was classified into the ICF domain and ICF code, and the type of ICF was classified into ICF core set and ICF tool. In addition, the application of WHODAS 2.0, which was made based on ICF, was also classified.

\section{Data Analysis}

Data analysis was conducted by summing the number of research papers according to the analysis criteria for 


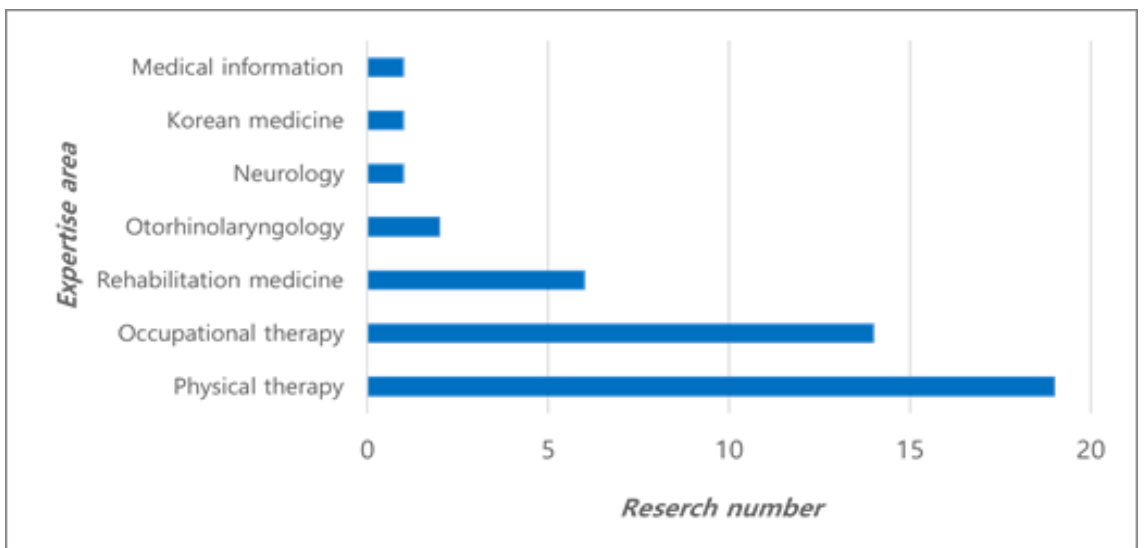

Fig. 1. Number of studies published according to the expertise field in domestic clinical research related to ICF.

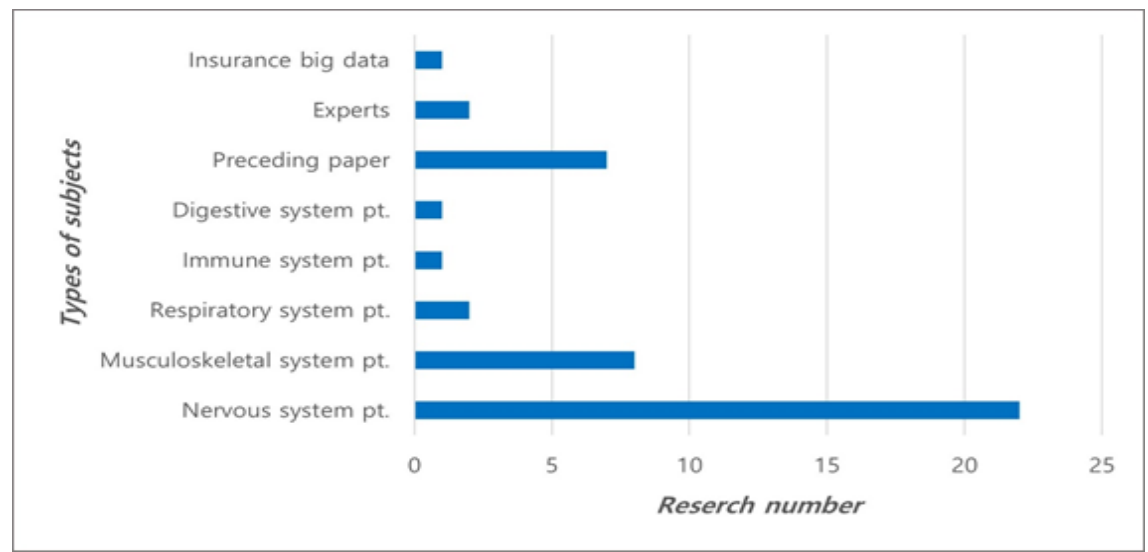

Fig. 2. Types and number of ICF-related research topics according to the field of expertise in domestic clinical research (pt.: patient).

coded data. Some research topics and the ICF domain used were classified by multiple analysis criteria, so duplicate frequencies were allowed in the data. The organized data were analyzed with the IBM SPSS 23 using multiple response cross-tabulation analysis for frequency and case percentages.

\section{Result}

\section{Analysis by Area of Expertise}

Over the past five years, many studies related to ICF have been conducted in the order of physical therapy (19 articles, $43.2 \%$ ), occupational therapy (14 articles, 31.8\%), and rehabilitation medicine (6 articles, 13.6\%) in domestic clinical field (Fig. 1, Annex 1).

\section{Analysis by Study Subject}

The subjects of the selected papers were mostly patients $(\mathrm{n}=34,77.3 \%$ ), followed in order by previous studies $(\mathrm{n}=7,15.9 \%)$, and related experts $(\mathrm{n}=2,4.5 \%)$ (Fig. 2). Papers on patients classified the diseases according to the body system. As a result, nervous system patients $(\mathrm{n}=$ $22,50 \%$ ) were the most common. Of these patients, stroke ( $\mathrm{n}=15,34.1 \%$ ) was the most common, followed by spinal 


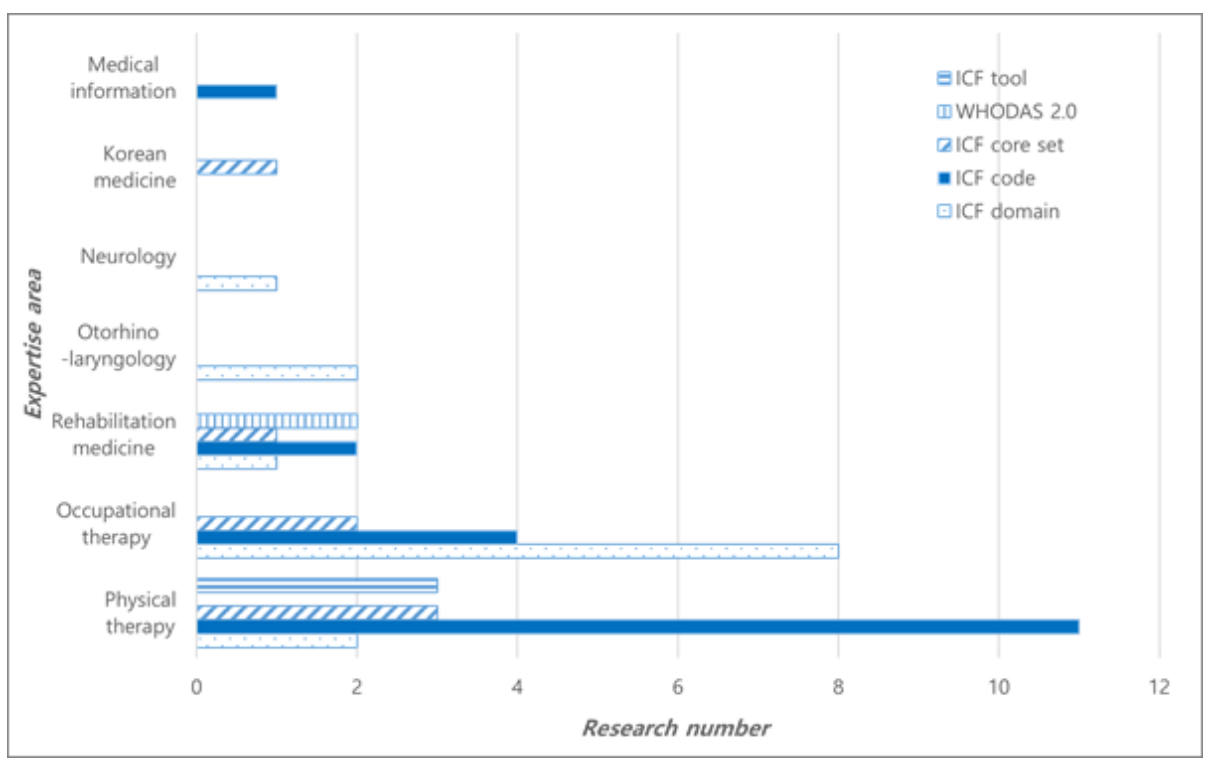

Fig. 3. Levels and types of ICF used in articles published according to the field of expertise in domestic clinical fields.

cord injury $(\mathrm{n}=2,2.3 \%)$. Cerebral palsy, Parkinson's disease, dementia, peripheral nerve injury, and psychiatric patients were also classified as nervous system patients.

There were eight studies targeting patients with the musculoskeletal system, accounting for $18.2 \%$ of the total. Back pain, shoulder pain, neck pain, temporomandibular joint pain, adhesive capsulitis, rotator cuff tear, multiple knee ligament injury, and scoliosis were also included in musculoskeletal system patients. In the respiratory system patients, one patient each of the pharyngeal, larynx, and benign mucosal diseases related to the vocal organs was observed. In the preceding papers that were the subject of the review study, one paper each was related to stroke $(\mathrm{n}=3)$ and cerebral palsy $(\mathrm{n}=2)$, and dementia and specific treatment-related papers were identified. In the preceding papers reviewed, there were three and two papers on stroke and cerebral palsy, respectively, and one paper each related to dementia and specific treatment was identified.

\section{Analysis by Research Topic}

The most common research subjects used ICF as a measurement tool $(\mathrm{n}=21,47.7 \%)$ to evaluate the functioning level and characteristics of the study subjects, followed in order by ICF case studies $(\mathrm{n}=11,25 \%)$ and review studies related to ICF targeting a specific disease $(\mathrm{n}=8,18.2 \%)$. For the analysis of the functioning measurement tool, the five studies that performed the subject's evaluation were duplicated in the study using ICF as a measurement tool and the measurement tool analysis. Table 1 lists the research topics for each expertise area.

\section{Analysis according to the Domain of ICF Utilized}

Table 2 lists the overlapping analysis of the ICF components used in the selected ICF-related domestic studies. The most used domain was activity and participation with 43 cases (40.9\%), followed by the body function domain with 33 cases (30.8\%).

\section{Analysis according to the Level and Type of ICF Utilized}

In the research papers of this study, ICF codes ( $\mathrm{n}=$ $18,40.9 \%)$ were used more than the ICF domain $(n=$ 
Table 1. Types and Number of ICF Research Topics Used in Each Expertise Area in Domestic Clinical Research Related to ICF

* number $(\%)$

\begin{tabular}{|c|c|c|c|c|c|c|c|c|}
\hline & $\begin{array}{c}\text { Measurement } \\
\text { tool }\end{array}$ & $\begin{array}{c}\text { Tool } \\
\text { development }\end{array}$ & $\begin{array}{l}\text { Case } \\
\text { study }\end{array}$ & $\begin{array}{c}\text { Tool } \\
\text { analysis }\end{array}$ & $\begin{array}{l}\text { Intervention } \\
\text { plan }\end{array}$ & Review & $\begin{array}{l}\text { Insurance } \\
\text { big data }\end{array}$ & Total by area \\
\hline Physical therapy & $11(42.3)^{*}$ & $2(7.7)$ & $9(34.6)$ & $4(15.4)$ & & & & $26(59.1)$ \\
\hline Occupational therapy & $3(21.4)$ & $2(14.3)$ & & & $1(7.1)$ & $7(50.0)$ & $1(7.1)$ & $14(31.9)$ \\
\hline Rehabilitation medicine & $4(66.67)$ & $1(16.7)$ & $1(16.7)$ & & & & & $6(13.6)$ \\
\hline Otorhinolaryngology & $2(66.7)$ & 1(33.)3 & & & & & & 3 \\
\hline Neurology & & & & & & $1(100)$ & & 1 \\
\hline Korean medicine & & & $1(100.0)$ & & & & & 1 \\
\hline Medical information & $1(100.0)$ & & & & & & & 1 \\
\hline Total & $21(47.7)$ & $6(54.5)$ & $11(25.0)$ & $4(9.1)$ & $1(2.3)$ & $8(18.2)$ & $1(2.3)$ & $44(100.0)$ \\
\hline
\end{tabular}

Table 2. Types and Number of ICF Domains Used in Each Expertise Area in Domestic Clinical Articles (Duplicate Frequency) ${ }^{*}$ number $(\%)$

\begin{tabular}{cccccc}
\hline & Body function & Body structure & Activity \& Participation & Environmental factor & Total by area \\
\hline Physical therapy & $14(31.1)^{*}$ & $4(8.9)$ & $19(42.2)$ & $8(17.8)$ & $45(42.1)$ \\
Occupational therapy & $12(33.3)$ & $2(5.6)$ & $13(36.1)$ & $9(25.0)$ & $36(33.6)$ \\
Rehabilitation medicine & $4(26.7)$ & $3(20.0)$ & $6(40.0)$ & $2(13.3)$ & $15(14.0)$ \\
Otorhinolaryngology & & & $2(100.0)$ & & $2(1.9)$ \\
Neurology & $1(50.0)$ & & $1(50.0)$ & & $2(1.9)$ \\
Korean medicine & $1(25.0)$ & $1(25.0)$ & $1(25.0)$ & $1(25.0)$ & $4(3.7)$ \\
Medical information & $1(33.3)$ & & $1(33.3)$ & $1(33.3)$ & $3(2.8)$ \\
\hline Total & $33(30.8)$ & $10(9.3)$ & $43(40.2)$ & $21(19.6)$ & $107(100)$ \\
\hline
\end{tabular}

$14,31.8 \%)$. As for the ICF type, the ICF core set $(\mathrm{n}=$ $7,15.9 \%)$ and ICF tool $(\mathrm{n}=3,6.8 \%)$ were observed.

\section{Discussion}

This study examined the trends of ICF-related research conducted in the domestic clinical field to suggest a utilization plan that can be used actively as a standard classification in the clinical field. This study analyzed the papers that met the inclusion criteria among research papers reported in the clinical field over the past five years. The research papers were analyzed after classifying them into specialized areas, research subjects, research topics, used
ICF domains, and used ICF levels and types. The following discussions can be made based on the results obtained. Physical therapy was the specialty of the clinical field, where ICF-related research was conducted the most, followed by occupational therapy and rehabilitation medicine. This was like the results of previous studies [11,12]. These results were attributed to the collection of functioningrelated information to understand the patient's health condition and disability in these areas and the use of ICF for this purpose $[13,14]$. In many clinical settings, physical therapy is an important part of a multidisciplinary rehabilitation setting that aims to encourage individuals with health conditions to achieve and maintain the optimal 
functioning and encourage full participation of individuals in all aspects of life in their environment [15]. Hence, it is believed that the use of ICF in physical therapy was the most common. Research on otolaryngology and Korean medicine, which were not observed in previous studies, was reported, which means that the field of expertise for conducting ICF-related research is expanding $[16,17]$.

The papers analyzed in this study mostly involved nervous system patients, such as stroke, spinal cord injury, and dementia. These results are like those of previous studies [18], and it is believed that ICF-related studies were mainly conducted in a rehabilitation setting, including physical therapy and occupational therapy. Many studies were conducted on stroke patients because stroke is one of the most disabling conditions caused by impairments of the body functions and structures, limitation of activities, and restriction of participation due to loss of neurological function $[19,20]$. Overall, communication of functioning performance-related information using ICF among experts will be more active if more diverse types of patients are examined.

Most research subjects using ICF to evaluate patients' functioning and characteristics were similar to previous studies [11,12]. This reflects the characteristics of the clinical field and is an essential part of understanding the patient's health condition.

Case study topics for various diseases were observed in physical therapy, and this trend was like that of previous studies. In these studies, ICF was used for patient intervention goals, planning, evaluation, and prognosis [21-23]. Moreover, readers can easily apply ICF to patient treatment and evaluation using these case studies.

Research topics that analyze the tool by linking the concept contained in the items of the functioning measurement tool into ICF code, which is typically used in the physical therapy area, and the research topic that confirms the possibility of coding by linking the contents of the medical records into ICF code were also observed
[24-27]. If the existing measurement tool relates to the international standard classification, ICF, communication between experts can be facilitated, and data comparison between institutions and countries is possible, contributing significantly to data standardization. In addition, it is cost-effective because it is possible to utilize existing tools rather than develop new tools for the standardization of medical information [25].

Research topics using ICF were also observed during item development for a new functioning measurement tool $[28,29]$. Research topics that applied ICF codes to the content development of daily life guideline applications were also confirmed [30]. This confirms the application of ICF, a biopsychosocial model, to the development of tools with various contents.

The most widely used ICF area in the entire specialized area of the research paper was in the order of activity, participation, and physical function, which is similar to previous studies $[11,12]$. On the other hand, although there was relatively less information on environmental factors than other components, the application increased more than in previous studies [31]. All ICF domains should be applied to profile functioning. In some studies, however, specific domains were selected and applied [32,33]. Even if there are difficulties in performing the function, modification of the environment can compensate for this, so the collection of related information is considered essential for reducing the activity limitations and restrictions on the activities and participation of subjects.

In physical therapy and rehabilitation medicine, the ICF code was used more than the ICF domain. This is thought to reflect the recommendation to use a lower-level code to obtain more detailed functioning information because of the characteristics of the clinical field [34-36]. The ICF code suitable for the purpose and the level of the corresponding code should be appropriately selected.

This study had some limitations. There may be articles in clinical areas omitted because the search was conducted 
using the related search terms in the four databases: RISS, KISS, NDSL, and PubMed. In addition, research in other clinical areas was not included in the analysis because the subjects were papers published in journals registered with the National Research Foundation of Korea and candidate journals. Nevertheless, it is considered a meaningful approach to examine the research trends according to the expertise areas of the domestic clinical field and to find a way to activate the use of ICF based on research published within the last five years.

After reviewing ICF-related research in the domestic clinical field, the following application plan is proposed to promote the use of ICF, an international standard classification, in the clinical field.

The unification of terms is important for communication between various fields, but in domestic clinical practice, the ICF terms translated into Korean were not unified. The study reported in the Korean medicine field used the Korean Standard Classification of Functioning, Disability, and Health (KCF). This is the standard classification of the health sector established by Statistics Korea. It is based on the ICF and is a classification system that reflects the domestic situation. Classifying health and health-related information and functioning information using $\mathrm{KCF}$ as a unified term is believed to help communication between various specialized fields and promote reliable domestic statistical data accumulation.

For smooth communication between the clinical areas of expertise, it is important to select an appropriate ICF code for patient evaluation and use the outcome with the qualifier applied. For this, research on standardized education for ICF is required. In addition, developing a casebook using ICF that reflects the characteristics of domestic expertise areas and includes Korean culture will help enhance the understanding of ICF.

Research related to developing education or evaluation tools that map the characteristics of various subjects, such as patients, guardians, children, and health promotion program subjects, into ICF is needed. The system should be designed so that users can easily understand and conveniently access it. Research related to the development of a computer program that is easy to input, output, compare, and store functioning data using ICF is required. Furthermore, research is needed to develop a program and instructions that can accurately present the ICF code and classify the degree of function performance based on the input functioning information.

Research related to establishing a system that can share functioning-related information in various institutions, such as hospitals, welfare centers, schools, and nursing homes, is also required. It is contemplated that the sharing of such information can be used to plan and provide appropriate services to the subject. In addition, the accumulation of information can be utilized for health-related policy establishment and budgeting. Lastly, research should be conducted nationally because the above studies require collaboration among experts in various fields.

\section{Conclusion}

This study examined the trends in ICF-related research conducted in the domestic clinical field over the past five years to find ways to utilize them. In physical therapy, occupational therapy, and rehabilitation medicine, ICF-related research has been conducted targeting patients and previous papers. To promote the use of ICF in the domestic clinical field, the following studies are needed: unification of ICF terminology, ICF standardized education, development of ICF use casebook, tool analysis and development using ICF, development of ICF coding program and guidelines, the establishment of a linkage system between related organs, and multidisciplinary research at the national level. 


\section{References}

[1] WHO. International classification of functioning, disability and health. 2001.

[2] Stucki G, Pollock A, Engkasan JP, et al. How to use the International Classification of Functioning, Disability and Health as a reference system for comparative evaluation and standardized reporting of rehabilitation interventions. Eur J Phys Rehabil Med. 2019;55(3): 384-94.

[3] Lee HJ, Song JM. Analysis of the characteristics of Patients with Chronic Low Back Pain Using the ICF Concept. J Kor Phys Ther. 2013;25(5):282-7.

[4] Edwards T, Michelsen AS, Fakolade AO, et al. Exercise training improves participation in persons with multiple sclerosis: A systematic review and meta-analysis. J Sport Health Sci. 2021.

[5] Scura D, Piazza VM. Disability Evaluation. StatPearls. Treasure Island (FL). StatPearls Publishing Copyright (C) 2021, StatPearls Publishing LLC. 2021.

[6] Jette AM. Toward a common language for function, disability, and health. Phys Ther. 2006;86(5):726-34.

[7] Prodinger B, Tennant A, Stucki G. Standardized reporting of functioning information on ICF-based common metrics. Eur J Phys Rehabil Med. 2018;54(1):110-7.

[8] Prodinger B, Cieza A, Oberhauser C, et al. Toward the International Classification of Functioning, Disability and Health (ICF) Rehabilitation Set: A Minimal Generic Set of Domains for Rehabilitation as a Health Strategy. Arch Phys Med Rehabil. 2016;97(6):875-84.

[9] Engkasan JP, Ahmad-Fauzi A, Sabirin S, et al. Mapping the primary outcomes reported in Cochrane systematic reviews regarding stroke with the International Classification of Functioning, Disability and Health domains: current trend and future recommendations. Eur J Phys Rehabil Med. 2019;55(3):378-83.

[10] Tomandl J, Heinmüller S, Selb M, et al. Laying the foundation for a Core Set of the International Classification of Functioning, Disability and Health for communitydwelling older adults in primary care: relevant categories of their functioning from the research perspective, a scoping review. BMJ Open. 2021;11(2):e037333.

[11] Lee HJ, Song JM. An Overview of the ICF's Use in Korea. J Kor Phys Ther. 2015;27(5):356-63.

[12] Song JM. A Review of Domestic Research Trends Related to the International Classification of Functioning, Disability and Health (ICF): 2015-2020. J Korean Soc Phys Med. 2021;16(3):65-80.

[13] Michener LA. Patient- and clinician-rated outcome measures for clinical decision making in rehabilitation J Sport Rehabil. 2011;20(1):37-45.

[14] Lee HJ, Song JM. Which Information is Commonly Used for Patients with Stroke at Rehabilitation Settings? J Kor Phys Ther. 2015;27(6):392-9.

[15] Stucki G, Cieza A, Melvin J. The International Classification of Functioning, Disability and Health (ICF): a unifying model for the conceptual description of the rehabilitation strategy. J Rehabil Med. 2007;39(4):279-85.

[16] Lee SJ, Choi HC, Kim HH, et al. Korean Version of the Voice Activity and Participation Profile (K-VAPP). Communication Sciences and Disorders. 2016;21(4): 695-708.

[17] Kim MK. A case report of a patient with spinal cord infarction treated by Korean medicine combined with conventional medicine: An evaluation using Korean Standard Classification of Functioning, Disability and Health (KCF). JKM. 2018;39(3):89-100.

[18] Choi JH, Park JK, Park SH, et al. A Study to Develop the ICF Core Set for Developmental Disabilities. Journal of Educational Innovation Research. 2018;28(4):265-94.

[19] Adamson J, Beswick A, Ebrahim S. Is stroke the most common cause of disability? J Stroke Cerebrovasc Dis. 2004;13(4):171-7.

[20] Goljar N, Burger H, Vidmar G, et al. Measuring patterns of disability using the International Classification of Functioning, Disability and Health in the post-acute stroke 
rehabilitation setting. J Rehabil Med. 2011;43(7):590-601.

[21] Kim JC, Lee JA. A PNF intervention strategy with ICF tool applied for improvement of dressing in a patient with rotator cuff syndrome : A case report. J Korean Soc Phys Med. 2018;13(3):49-60.

[22] Song MS, Kim BR, Kim CH, et al. A Case Report of a Proprioceptive Neuromuscular Facilitation Intervention Strategy Applied with an ICF Tool in a Patient with Anterior Cruciate Ligament Reconstruction. PNF \& Mov. 2017;15(1):1-11.

[23] Kang TW, Kim TY. A Case report of PNF strategy applied ICF tool on upper extremity function for patient adhesive capsulitis. J Korean Soc Phys Med. 2017;12(4):19-28.

[24] Lee HJ, Song JM. Mapping Items of Functioning Questionnaires into the International Classification of Functioning, Disability and Health: Low Back Pain. J Kor Phys Ther. 2016;28(5):321-7.

[25] Song JM, Lee HJ. Mapping Items of Functioning Questionnaires into the International Classification of Functioning, Disability and Health: Stroke. J Kor Phys Ther. 2016;28(5):341-7.

[26] Lee HJ, Song JM. Linking of Items in Two Function-related Questionnaires to the International Classification of Functioning, Disability and Health: Shoulder Pain. J Kor Phys Ther. 2018;30(6):239-46.

[27] Lee HJ, Song JM. Functioning Characteristics of Patients with Neck Pain: ICF Concept Based. J Kor Phys Ther. 2019;31(4):242-7.

[28] Park CH, Pyun SB, Seung DY, et al. Development of a Short Version of ICF Core Set for Stroke Adapted for Rehabilitation in Korea: a Preliminary Study. Brain Neurorehabil. 2021;14(1):1-9.

[29] Song YJ, Park EJ, Jung JY. Development of Occupational
Therapy Intervention Terminology for Dementia. Korea J. Occup. Ther. 2021;29(1):71-86.

[30] Song YH, Jung CO, Lee HM. Development of an application for Activities of daily living guidelines for stroke patients and caregivers. Journal of KOEN 2017;11(5):245-52.

[31] Song JM, Lee HJ. Which Information of ICF Was Collected to Understand Our Clients? J Kor Phys Ther. 2016; 28(2):77-87.

[32] Sung HY, Ko SH, Lee YC, et al. Factors Analysis Associated with Body Function and Activity \& Participations in patients with stroke : Using International Classification of Functioning, Disability and Health (ICF). J Kor Aging Friendly Industry. 2018;10(2):107-15.

[33] Im JW, Yoon SK, Lee YM. A Preliminary Study on the Correlation Between ICF and Functions of Upper Limbs of Chronic Stroke Patients : ICF Activities, Participations, and Environmental Factors. PNF and Movement. 2018;16(3):485-93.

[34] Lee JA, Lee HM. The Effect of Dual Task Training based on the International Classification of Functioning, Disability, and Health on Walking Ability and SelfEfficacy in Chronic Stroke . J Korean Soc Phys Med. 2017;12(1):121-9.

[35] Lee JA, Kim JC. The Coordinative Locomotor Training Intervention Strategy Using the ICF Tool to Improve the Standing Posture in Scoliosis: A Case Report. J Kor Phys Ther. 2021;33(1):7-15.

[36] Kim CY, Kwon JW. Intervention Strategy Applied ICF Checklists for Sitting Cross-Legged in Patient with Multiple Ligament Knee Injury: Single Subject Study. J Kor Phys Ther. 2021;33(3):168-77. 
Annex 1 List of Subject Articles

\begin{tabular}{|c|c|c|c|c|c|c|c|}
\hline No. & Title & Application of ICF & ICF level/type & Area & Author & Journal & Year \\
\hline 1 & $\begin{array}{l}\text { Mapping Items of Functioning Questionnaires into the International } \\
\text { Classification of Functioning, Disability and Health: Stroke }\end{array}$ & $\begin{array}{l}\text { Tool analysis, } \\
\text { Measurement }\end{array}$ & ICF code & PT & Song JM, Lee HJ & J Kor Phys Ther & 2016 \\
\hline 2 & $\begin{array}{l}\text { Which Information of ICF was Collected to Understand Our } \\
\text { Clients? }\end{array}$ & Measurement & ICF core set & PT & Song JM, Lee HJ & J Kor Phys Ther & 2016 \\
\hline 3 & $\begin{array}{l}\text { Mapping Items of Functioning Questionnaires into the } \\
\text { International Classification of Functioning, Disability and Health: } \\
\text { Low Back Pain }\end{array}$ & $\begin{array}{l}\text { Tool analysis, } \\
\text { Measurement }\end{array}$ & ICF code & PT & Lee HJ, Song JM & J Kor Phys Ther & 2016 \\
\hline 4 & $\begin{array}{l}\text { An ICF-Core Sets for Children and Youth with Cerebral Palsy } \\
\text { Based Approach From a Physical Therapist Perspective: A } \\
\text { Single Case Study }\end{array}$ & Case study, & ICF core set & PT & Kim JH, Kim TH & PTK & 2016 \\
\hline 5 & $\begin{array}{l}\text { Case Report of Physical Therapy using Proprioceptive } \\
\text { Neuromuscular Facilitation for Activity Improvement in a Patient } \\
\text { with Parkinson's Disease }\end{array}$ & Case study & ICF code & PT & Sin JW, Kim JJ & PNF \& Mov & 2016 \\
\hline 6 & $\begin{array}{l}\text { Development of an Application for Activities of Daily Living } \\
\text { Guidelines for Stroke Patients and Caregivers }\end{array}$ & Tool development & ICF code & PT & Song YH & $\begin{array}{c}\text { Journal of } \\
\text { KOEN }\end{array}$ & 2017 \\
\hline 7 & $\begin{array}{l}\text { The Effect of Dual Task Training based on the International } \\
\text { Classification of Functioning, Disability, and Health on Walking } \\
\text { Ability and Self-Efficacy in Chronic Stroke }\end{array}$ & Measurement & ICF code & PT & Lee JA, Lee HM & $\begin{array}{l}\text { J Korean Soc } \\
\text { Phys Med }\end{array}$ & 2017 \\
\hline 8 & $\begin{array}{l}\text { A Case Report of a Proprioceptive Neuromuscular Facilitation } \\
\text { Intervention Strategy Applied with an ICF Tool in a Patient with } \\
\text { Anterior Cruciate Ligament Reconstruction, Song MS, Kim BR, } \\
\text { Kim CH, et al., PNF \& Mov, } 2017\end{array}$ & Case study & ICF tool & PT & $\begin{array}{l}\text { Song MS, Kim BR, } \\
\text { Kim } \mathrm{CH} \text {, et al. }\end{array}$ & PNF \& Mov & 2017 \\
\hline 9 & $\begin{array}{l}\text { A Case Report of PNF Strategy Applied ICF Tool on Upper } \\
\text { Extremity Function for Patient Adhesive Capsulitis }\end{array}$ & Case study & ICF tool & PT & Kang TW, Kim TY & $\begin{array}{l}\text { J Korean Soc } \\
\text { Phys Med }\end{array}$ & 2017 \\
\hline 10 & $\begin{array}{l}\text { Predictive Analyses for Activities of the Upper Extremity and } \\
\text { Daily Living based on Impairment of the Upper Extremity in } \\
\text { People with Stroke - Preliminary Study using Clinical Scales }\end{array}$ & Measurement & ICF domain & PT & Jung YI, Woo YK & PNF \& Mov & 2018 \\
\hline 11 & $\begin{array}{l}\text { The Correlation Between ICF and Clinical Assessment Tools } \\
\text { in Chronic Stroke Patients }\end{array}$ & $\begin{array}{l}\text { Tool analysis, } \\
\text { Measurement }\end{array}$ & ICF code & PT & $\begin{array}{l}\text { Lee JA, Lee HM, } \\
\text { Kim JC }\end{array}$ & $\begin{array}{l}\text { J SPE EDU \& } \\
\text { REHAB SCI }\end{array}$ & 2018 \\
\hline 12 & $\begin{array}{l}\text { A Preliminary Study on the Correlation Between ICF and } \\
\text { Functions of Upper Limbs of Chronic Stroke Patients : ICF } \\
\text { Activities, Participations, and Environmental Factors }\end{array}$ & Measurement & ICF code & PT & $\begin{array}{l}\text { Im JW, Yun SK, Lee } \\
\text { YM }\end{array}$ & PNF \& Mov & 2018 \\
\hline 13 & $\begin{array}{l}\text { The Effect of Coordinative Locomotor Training on Walking in } \\
\text { a Chronic Stroke Patient-A Single Subject Design- }\end{array}$ & Case study & ICF core set & PT & $\begin{array}{l}\text { Kim JC, Lee MK, } \\
\text { Lee JA, et al. }\end{array}$ & PNF \& Mov & 2018 \\
\hline 14 & $\begin{array}{l}\text { Influence of proprioceptive neuromuscular facilitation therapeutic } \\
\text { exercise on woman with temporomandibular joint disorder : a } \\
\text { case study }\end{array}$ & Case study & ICF domain & PT & Lee BK & $\begin{array}{l}\text { J. Exerc. } \\
\text { Rehabil. }\end{array}$ & 2018 \\
\hline 15 & $\begin{array}{l}\text { Linking of Items in Two Function-related Questionnaires to the } \\
\text { International Classification of Functioning, Disability and Health: } \\
\text { Shoulder Pain }\end{array}$ & $\begin{array}{l}\text { Tool analysis, } \\
\text { Measurement }\end{array}$ & ICF code & PT & Lee HJ, Song JM & J Kor Phys Ther & 2018 \\
\hline 16 & $\begin{array}{l}\text { A PNF Intervention Strategy with ICF Tool Applied for } \\
\text { Improvement of Dressing in a Patient with Rotator Cuff } \\
\text { Syndrome : A Case Report }\end{array}$ & Case study & ICF tool & PT & Kim JC, Lee JA & $\begin{array}{l}\text { J Korean Soc } \\
\text { Phys Med }\end{array}$ & 2018 \\
\hline 17 & $\begin{array}{l}\text { Functioning Characteristics of Patients with Neck Pain: ICF } \\
\text { Concept Based }\end{array}$ & $\begin{array}{l}\text { Tool analysis, } \\
\text { Measurement }\end{array}$ & ICF code & PT & Lee HJ, Song JM & J Kor Phys Ther & 2019 \\
\hline 18 & $\begin{array}{l}\text { Intervention Strategy Applied ICF Checklists for Sitting } \\
\text { Cross-Legged in Patient with Multiple Ligament Knee Injury: } \\
\text { Single Subject Study }\end{array}$ & Case study & ICF code & PT & Kim CY, Kwon JW & J Kor Phys Ther & 2021 \\
\hline 19 & $\begin{array}{l}\text { The Coordinative Locomotor Training Intervention Strategy } \\
\text { Using the ICF Tool to Improve the Standing Posture in Scoliosis: } \\
\text { A Case Report }\end{array}$ & Case study & ICF code & PT & Lee JA, Kim JC & J Kor Phys Ther & 2021 \\
\hline 20 & $\begin{array}{l}\text { A Study on Standard Terminology for Occupationa Therapy } \\
\text { Documentations Focusing on Korean-Type Medical Institutions }\end{array}$ & $\begin{array}{l}\text { Terminology } \\
\text { development }\end{array}$ & ICF code & OT & Song YJ & $\begin{array}{l}\text { Korea J. Occup. } \\
\text { Ther. }\end{array}$ & 2016 \\
\hline
\end{tabular}




\begin{tabular}{|c|c|c|c|c|c|c|c|}
\hline No. & Title & Application of ICF & ICF level/type & Area & Author & Journal & Year \\
\hline 21 & $\begin{array}{l}\text { Literature Review of Korean Occupational Therapy Research for } \\
\text { Children and Youth Regarding the International Classification of } \\
\text { Functioning: Focusing on the Korean Society of Occupational Therapy }\end{array}$ & Literature Review & ICF domain & OT & Kim SY, Min YS & $\begin{array}{l}\text { Korea J. Occup. } \\
\text { Ther. }\end{array}$ & 2016 \\
\hline 22 & $\begin{array}{l}\text { Analysis of Medical Rehabilitation's Fee Using National Health } \\
\text { Insurance Service's Big Data: Focusing on ICF Model }\end{array}$ & Status Analysis & ICF domain & OT & Cha YJ & $\begin{array}{l}\text { Korea J. Occup. } \\
\text { Ther. }\end{array}$ & 2017 \\
\hline 23 & $\begin{array}{l}\text { Social Support and Relations according to Personality Changes } \\
\text { in Stroke Elderly Patients }\end{array}$ & Measurement & ICF code & OT & Kim HY & OTAD & 2017 \\
\hline 24 & $\begin{array}{l}\text { A Systematic Review of Assessment Tools of Activities of Daily } \\
\text { Living for Stroke Patients }\end{array}$ & Literature Review & ICF domain & OT & Kang JW, Park JH & TSNR & 2017 \\
\hline 25 & $\begin{array}{l}\text { The Effect of Health-Related Factors of Stroke Patients in Local } \\
\text { Community on Their Wellness }\end{array}$ & Measurement & ICF core set & OT & Kim HM & $\begin{array}{l}\text { Korea J. Occup. } \\
\text { Ther. }\end{array}$ & 2018 \\
\hline 26 & $\begin{array}{l}\text { Therapeutic Intervention for Visuo-Spatial Neglect after Stroke: } \\
\text { A Meta-Analysis of Randomized Controlled Trials }\end{array}$ & Literature Review & ICF domain & OT & Kwon JS & $\begin{array}{l}\text { Osong Public } \\
\text { Health Res } \\
\text { Perspect }\end{array}$ & 2018 \\
\hline 27 & $\begin{array}{l}\text { Analysis of Factors Restricting Return to Work for Stroke: } \\
\text { Based on ICF }\end{array}$ & Measurement & ICF core set & OT & Nam JH & $\begin{array}{l}\text { Korea J. Occup. } \\
\text { Ther. }\end{array}$ & 2019 \\
\hline 28 & $\begin{array}{l}\text { The effect of instrumental activities of daily living program on } \\
\text { general self-efficacy, motivation for rehabilitation, social support } \\
\text { in a patient with subacute stroke }\end{array}$ & Measurement & ICF code & OT & Choi MK & KSIM & 2019 \\
\hline 29 & $\begin{array}{l}\text { Rehabilitation Interventions for Social Participation of Chronic } \\
\text { Stroke: A Systematic Review and Meta-Analysis }\end{array}$ & Literature Review & ICF domain & OT & Kim EJ & J Rehab Resea & 2019 \\
\hline 30 & $\begin{array}{l}\text { A systematic review of clinical assessment tools used to measure } \\
\text { feeding intervention results in children with cerebral palsy }\end{array}$ & Literature Review & ICF domain & OT & Seo SM & JDCS & 2019 \\
\hline 31 & $\begin{array}{l}\text { Effects of Cognitive Intervention Activities for the Elderly with } \\
\text { Dementia in Korea: A Meta-Analysis }\end{array}$ & Literature Review & ICF domain & OT & Kwon JS & $\begin{array}{l}\text { J Health Info } \\
\text { Stat }\end{array}$ & 2019 \\
\hline 32 & $\begin{array}{l}\text { A Systematic Review of Sensory Integration Intervention for } \\
\text { Children in Korea }\end{array}$ & Literature Review & ICF domain & OT & Hong EK & $\begin{array}{l}\text { J Kor Sensory } \\
\text { Integration }\end{array}$ & 2020 \\
\hline 33 & $\begin{array}{l}\text { Development of Occupational Therapy Intervention } \\
\text { Terminology for Dementia }\end{array}$ & $\begin{array}{l}\text { Terminology } \\
\text { development }\end{array}$ & ICF code & OT & Song YJ & KSOT & 2021 \\
\hline 34 & $\begin{array}{l}\text { Monitoring of Functioning Status in Subjects With Chronic Stroke } \\
\text { in South Korea Using WHODAS II }\end{array}$ & Measurement & WHODAS 2.0 & $\mathrm{RM}$ & Kwon SY & ARM & 2016 \\
\hline 35 & $\begin{array}{l}\text { Dilemmas of Korean Athletes With a Spinal Cord Injury to } \\
\text { Participate in Sports: A Survey Based on the ICF Core Set for } \\
\text { Spinal Cord Injury }\end{array}$ & Measurement & ICF core set & $\mathrm{RM}$ & $\begin{array}{l}\text { Nam JS, Lee KE, } \\
\text { Jun AY, Parke CS, } \\
\text { et al. }\end{array}$ & $\begin{array}{l}\text { Ann Rehabil } \\
\text { Med }\end{array}$ & 2016 \\
\hline 36 & $\begin{array}{l}\text { A Comprehensive Rehabilitation Approach in a Patient With } \\
\text { Serious Neuropsychiatric Systemic Lupus Erythematosus }\end{array}$ & Measurement & ICF code & $\mathrm{RM}$ & Kong YJ & ARM & 2016 \\
\hline 37 & Is WHODAS 2.0 Useful for Colorectal Cancer Survivors? & Measurement & WHODAS 2.0 & $\mathrm{RM}$ & Lee $\mathrm{HH}$ & ARM & 2017 \\
\hline 38 & $\begin{array}{l}\text { Factors analysis associated with body function and activity \& } \\
\text { participations in patients with stroke : using international } \\
\text { classification of functioning, disability and health (ICF) }\end{array}$ & Measurement & ICF domain & $\mathrm{RM}$ & $\begin{array}{l}\text { Seong HY, Ko SH, } \\
\text { Lee EC, et al. }\end{array}$ & $\begin{array}{l}\text { J Kor Aging } \\
\text { Friendly } \\
\text { Industry }\end{array}$ & 2018 \\
\hline 39 & $\begin{array}{l}\text { Development of a Short Version of ICF Core Set for Stroke } \\
\text { Adapted for Rehabilitation in Korea: a Preliminary Study }\end{array}$ & Tool development & ICF code & RM & Park $\mathrm{CH}$ & $\begin{array}{c}\text { Brain } \\
\text { Neurorehabil }\end{array}$ & 2021 \\
\hline 40 & $\begin{array}{l}\text { Korean Version of the Voice Activity and Participation Profile } \\
\text { (K-VAPP): }\end{array}$ & $\begin{array}{l}\text { Tool development, } \\
\text { Measurement }\end{array}$ & ICF domain & ENT & Lee SJ & CSD & 2016 \\
\hline 41 & $\begin{array}{l}\text { A Comparison of Voice Activity and Participation Profiles } \\
\text { according to the Patterns of Professional Voice Use }\end{array}$ & Measurement & ICF domain & ENT & Lee SJ & CSD & 2019 \\
\hline 42 & Clinical Scales for Peripheral Neuropathy - Revision 2021 & Tool analysis & ICF domain & NR & Kim JE & $\begin{array}{l}\text { J Korean Neurol } \\
\text { Assoc }\end{array}$ & 2021 \\
\hline 43 & $\begin{array}{l}\text { A case report of a patient with spinal cord infarction treated } \\
\text { by Korean medicine combined with conventional medicine: An } \\
\text { evaluation using Korean Standard Classification of Functioning, } \\
\text { Disability and Health (KCF) }\end{array}$ & Case study & ICF core set & KM & Kim MK & JKM & 2018 \\
\hline 44 & $\begin{array}{l}\text { An Exploratory Study on ICF Core Set Clinical Apply for Mental } \\
\text { Illness Psychiatric Hospital in Korea }\end{array}$ & Measurement & ICF code & MI & Jin MJ & $\begin{array}{l}\text { Disability \& } \\
\text { Employment }\end{array}$ & 2016 \\
\hline
\end{tabular}

PT: physical therapy, OT: Occupational therapy, RM: Rehabilitation medicine, ENT: Otorhinolaryngology, NR: Neurology, KM: Korean medicine, MI: Medical information 